\title{
History of Snakebite Envenomation Treatment and Contribution of Turkey to Global Antivenom Production
}

\author{
Can Sarica' (D), Leyla Topcu Sarica² (D), Tarik Ozturk² (D), Ruslan Abdullayev² (D) \\ 'Department of Neurosurgery, Health Sciences University Adiyaman Training and Research Hospital, Adiyaman, Turkey \\ ${ }^{2}$ Department of Anesthesiology and Reanimation, Health Sciences University Adiyaman Training and Research Hospital, Adiyaman, Turkey
}

Cite this article as: Sarica C, Topcu Sarica L, Ozturk T, Abdullayev R. History of Snakebite Envenomation Treatment and Contribution of Turkey to Global Antivenom Production. Eurasian J Emerg Med. 2018; 17 (4): 145-7.

Have you ever treated a case of human envenoming in the emergency department? If yes, did you pay attention to the origin of the antivenom used? Not so long ago, for until about a decade, we used to import antivenoms from various countries such as Egypt and Serbia. Antivenom treatment was available in only some wellequipped hospitals in our country; however, in this decade, things changed. We have been producing our own antivenoms, and they are available all over the country.

The first successful antivenin serum therapy dates back to 1895. Before that, antivenom treatment was not available, and people with a weak immune system died. The first horse-derived antivenom sera, produced by a protégé of Louis Pasteur named Albert Calmette, were used by Lépinay for antivenom treatment in present-day Vietnam (1). During that time, Calmette was living in Vietnam and decided to produce an antivenom after a flood forced cobras into a village near Saigon where they bit about 40 people and killed four (2). The preparation of the first antivenom involved the separation of the serum from the blood of hyperimmunized horses. Later, it was observed that the antibodies (immunoglobulins) were responsible for the therapeutic action (3); therefore, they were purified from the plasma and used instead of crude serum. Since then, immunoglobulin fragments have played an important role in the treatment. Despite the technological development, the principle of antivenom preparation has remained the same; however, for maximum quality, the production steps were standardized by the World Health Organization (WHO) in 2008 (4); we have explained this later.

In the clinical aspect, human envenoming is a recognized medical emergency with 421,000 to 2.5 million annual cases worldwide and
20,000 to 100,000 annual deaths (5). This condition is of particular interest to our country because there are approximately 40 different types of snakes classified under six families living in Turkey, which are described as follows (6):

- Typhlopidae: 1

- Leptotyphlopidae: 1

- Boidae: 1

- Colubridae: 27

- Viperidae: 9

- Elapidae: 1

Although there are some types belonging to the Colubridae family, which contain toxins dangerous to humans, only those belonging to the Viperidae and Elapidae families pose great danger to humans. Biting characteristics of the snakes from the Colubridae family make them far from being hazardous to humans (6).

Most of the venomous snakebites in our country occur in the East Black Sea, Southeastern Anatolia, East Anatolia, and Northwest Thrace regions. Of the 10 poisonous snakes, nine belong to Viperidae and one to Elapidae families; they have been described as follows (with Turkish names in the parentheses) (6):

- V. ammodytes (Boynuzlu engerek)

- V. barani (Baran engeregi)

- V. kaznakovi (Kafkas engeregi)

- V. lebetina (Koca engerek)

- V. pontica (Coruh engeregi)

- V. raddei (Agri engeregi)

ORCID IDs of the authors: C.S. 0000-0001-8419-7426; L.T.S. 0000-0003-1218-9018; T.0; 0000-0003-0012-6757; R.A. 0000-0002-1025-4026. 

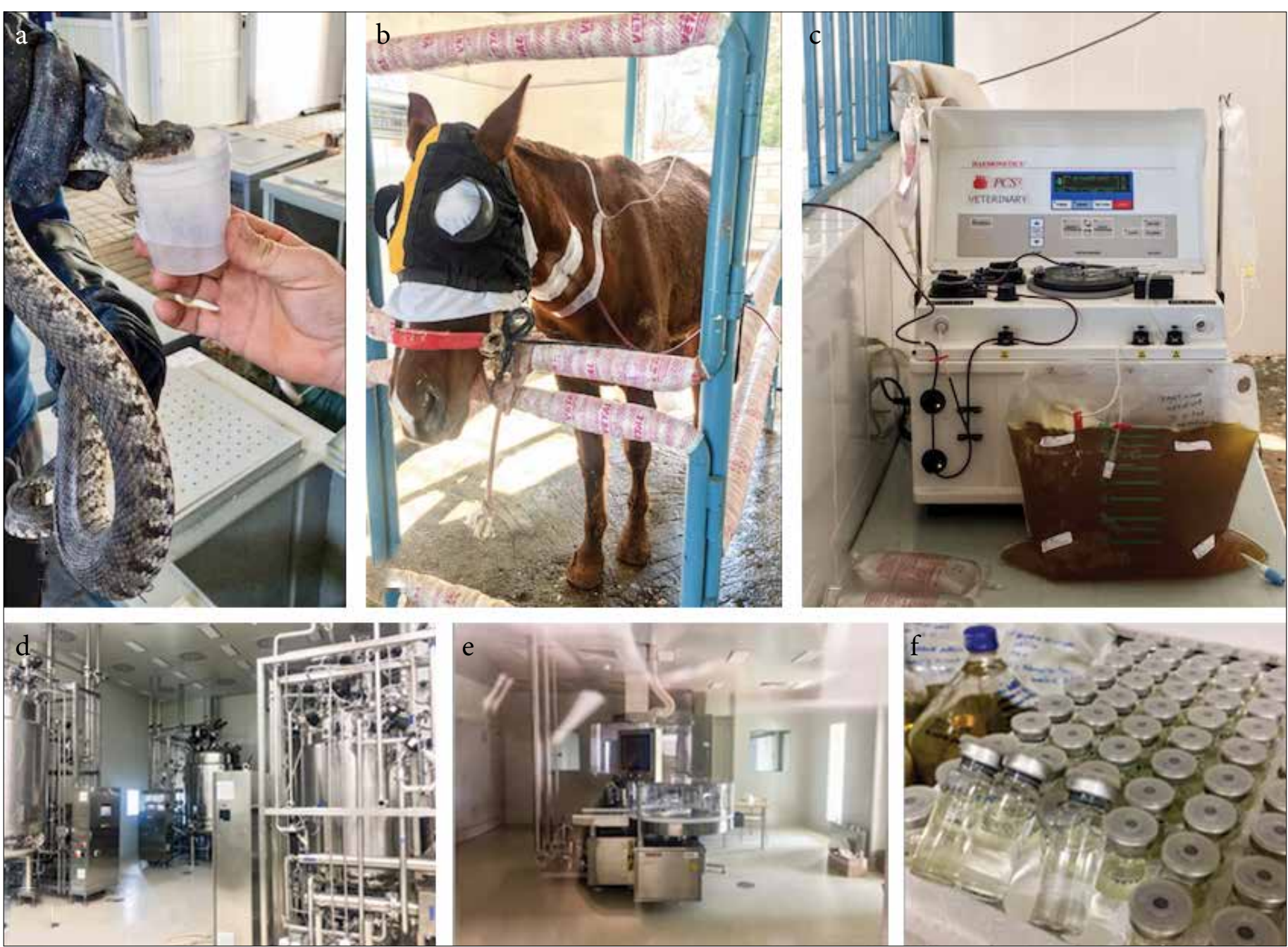

Figure 1. a-f. Steps of antivenom production. All snakes must be quarantined for at least 2 months in a special room before they qualify for milking. Venom is collected by snake milking (a), venom quality is checked in quality control laboratories using national venom references. Then venom doses are prepared using adjuvants following the World Health Organization guidelines on "Good Manufacturing Practices." Thereafter, the venom is injected into horses for immunization. Once the immune response to the immunizing venom mixture yields satisfactory antibody levels, the plasma is collected from the horses (b, c), the plasma is fractionated to extract the antivenom immunoglobulins. The bulk antivenom immunoglobulins are formulated (d) and filled into bottles in aseptic conditions (e), following macroscopic quality control tests, the potency of the antivenom is assessed by injecting it into rats. Bottled antivenoms are labeled and ready for release ( $f$ )

- V. ursinii (Kucuk engerek)

- V. wagneri (Vagner engeregi)

- V.xanthina (Seritli engerek)

- Walterinnesia Aegyptia (Col kobrasi)

The estimated economic burden of snakebites in Turkey is unclear. However, currently, we are fortunate regarding the treatment of this disease because one of the biggest antivenom manufacturers in the world, which is a candidate member of the WHO global antivenom producers database, was established in Adiyaman, Turkey, with $\$ 5$ million of investments in 2006 . The factory strictly conforms to the WHO guidelines for producing antivenom (4). This antivenom contains a mixture of horse-origin immunoglobulin fragments effective against three snakes from the Viperidae family: Macrovipera Lebetina, Montivipera Xanthina, and Vipera Ammodytes. These antivenins are found in the pharmacies of most hospitals where snake envenomation is endemic. In special circumstances, the antivenins can be obtained through communication with the
National Venom Consultation Center (Ulusal Zehir Danisma Merkezi) from the hospital or via personal telephones (Phone no. 114). The center supplies the antivenins through the national pharmacy chain via land or air transportation. This is the only authorized center for antivenin production in Turkey, and it obtained authorization in 2007.

Currently, there are 45 antivenom production centers listed in the WHO database of antivenom producers (7). These centers strictly adhere to the WHO guidelines and are listed in the database. Vetal Serum Turkey" has conformed to these guidelines and applied to be listed; we look forward for it to be listed herein in the near future.

For more than a decade, we are not only meeting our national needs but also exporting snake and scorpion antivenoms to a broad range of countries from Argentina to China. Following the listing in the $\mathrm{WHO}$ database, we are also expecting antivenin exportation to 
Europe and North America. We have summarized the production steps in Figure 1.

It should be considered that antivenin treatment can be more hazardous than the snake poison itself (8). Allergic reactions can be encountered during the treatment course. A cost-benefit analysis must be done before antivenin application. Adrenalin and $H_{1}$ and $\mathrm{H}_{2}$ receptor blockers should be kept ready. Skin test is controversial before antivenin application and is generally omitted because of false-positive and negative results. Serum sickness, which is a type III hypersensitivity reaction, must be considered as a late complication on days 3-21 of treatment.

In conclusion, producing antivenoms helps us treat our patients without struggling with drug insufficiency problem, which is a common problem worldwide since the closure of big manufacturers at the end of 20th century (9). To provide a better healthcare experience for our patients, we must achieve success in more areas of pharmaceutical production, as in this study.

Peer-review: Externally peer-reviewed.

Author Contributions: Concept - C.S., L.T.S., T.O., R.A.; Design - C.S., L.T.S., T.O., R.A.; Supervision - R.A.; Resources - C.S., L.T.S., T.O., R.A.; Materials - C.S., L.T.S., T.O., R.A.; Data Collection and/or Processing - C.S., L.T.S., R.A.; Analysis and/or Interpretation - C.S., R.A.; Literature Search - C.S., R.A.; Writing Manuscript C.S., R.A.; Critical Review - C.S., L.T.S., T.O., R.A.

Conflict of Interest: The authors have no conflict of interest to declare.
Financial Disclosure: Preparation for publication of this article is partly supported by Turkish Neurosurgical Society.

\section{References}

1. Calmette A. Sur le venin des serpents et sur l'emploi du sérum antivenimeux dans la thérapeutique des morsures venimeuses chez I'homme et chez les animaux. Ann Inst Pasteur. 1897; 12 :214-37.

2. Calmette A. Contribution à l'étude du venin des serpents. Immunisation des animaux et traitement de l'envenimation. Ann Inst Pasteur. 1894; 8: 275-91.

3. Pope CG. The action of proteolytic enzymes on the antitoxins and proteins in immune sera. I. True digestion of the proteins. Br J Exp Pathol. 1939; 20: 132-49.

4. World Health Organization W. Guidelines for the production control and regulation of snake antivenom immunoglobulins: 2016. Available from: URL: http://www.who.int/biologicals/expert_committee/Antivenom_ WHO_Guidelines_DJW_DEB_mn_cp.pdf.

5. Kasturiratne A, Wickremasinghe AR, de Silva N, Gunawardena NK, Pathmeswaran A, Premaratna $R$, et al. The global burden of snakebite: a literature analysis and modelling based on regional estimates of envenoming and deaths. PLoS Med. 2008; 5: e218. [CrossRef]

6. Cete Y, Goksu E, Cete E. Venomous snake bites. Turk J Emerg Med. 2005; 5: 92-7.

7. World Health Organization (WHO). Venomous snakes distribution and species risk categories: 2010. Available from: URL: http://apps.who.int/ bloodproducts/snakeantivenoms/database/.

8. Al B, Orak M, Aldemir M, Guloglu C. Snakebites in adults from the Diyarbakir region in southeast Turkey. Ulus Travma Acil Cerrahi Derg. 2010; 16: 210-4.

9. Williams DJ, Gutierrez JM, Calvete JJ, Wuster W, Ratanabanangkoon K, Paiva $\mathrm{O}$, et al. Ending the drought: new strategies for improving the flow of affordable, effective antivenoms in Asia and Africa. J Proteomics. 2011; 74: 1735-67. [CrossRef] 